\title{
Amelia Biagioni o el imprevisible trayecto de una experiencia poética alterna
}

\section{Resumen}

El presente artículo propone un recorrido de lectura crítica global en torno a los cinco poemarios publicados entre 1954 y 1995 por la escritora argentina Amelia Biagioni (1916 2000), poniendo especial énfasis en la condición alterna de su obra poética, tanto en relación con las tendencias estéticas dominantes en el campo literario de su época, como en el seno de su propia producción, caracterizada por un doble gesto simultáneo de ruptura y recomposición, de instauración y abolición complementarias. Se espera que el análisis discursivo de sus poemarios, así como de los procedimientos textuales fundamentales que componen su poesía, permita reflexionar acerca de su práctica poética de manera integral, reivindicando el carácter transgresivo/ disruptivo de su escritura con el objetivo de reafirmar, en última instancia, la singularidad de su producción.

Palabras claves

Biagioni - poesía argentina - siglo XX - crítica literaria - condición alterna - ruptura y recomposición - transgresión - singularidad.

\begin{abstract}
The present article proposes a critical analysis of the five books of poetry published between 1954 and 1995 by argentinian writer Amelia Biagioni (1916 - 2000), specially emphasizing the alternative condition of her poetic work, considered not only in relation with the esthetic tendencies that ruled the literary field of her time, but also with her own production, which is characterized by a double gesture of simultaneous rupture and recomposition, of complementary instauration and abolition. We expect that the discursive analysis of the author's literary work, among the textual procedures that she uses to write her poetry, will allow us to think over her poetic practice in a global manner, claiming the transgressive/disruptive nature of her writing with the final goal of reinforcing the singularity of her production
\end{abstract}

Keywords

Biagioni - argentine poetry - 20th centrury - literary criticism - alternative condition - rupture and recomposition - transgression - singularity. 


\section{Inicio del recorrido: aproximación a la autora y abordaje de su obra}

Delimitar los rasgos de la práctica poética de un autor constituye una tarea ardua y compleja, sobre todo frente a algunos casos en los que las categorizaciones y esquemas convencionales parecen resultar sencillamente insuficientes e inadecuados. No obstante, la pulsión por dilucidar y circunscribir nos lleva, como lectores y críticos, a insistir incansablemente, incluso sabiendo que nos enfrentamos a un desafío de proporciones mayúsculas, a una empresa cuyos resultados son tan inciertos como provisorios. Quizás sea esta complejidad la que explique la escasa difusión de una obra tan audaz e imprescindible como la de Amelia Biagioni (Gálvez, Santa Fé, 1916 - Buenos Aires, 2000). Pueden considerarse insuficientes los estudios críticos en torno a la obra de la poeta $\operatorname{argentina}^{1}$, sobre todo si se tiene en cuenta la singular riqueza de su trabajo y las diversas puertas de acceso por las cuales puede ingresarse a su universo poético. Uno de los factores fundamentales por los cuales Biagioni constituye una figura peculiar dentro del panorama literario argentino es su capacidad para superar las

\footnotetext{
${ }^{1}$ Los artículos críticos que abordan la poética de la autora son de por sí escasos, y de una gran variedad y heterogeneidad, lo cual dificulta la posibilidad de establecer un panorama crítico de carácter global en torno a su producción. Asimismo, las publicaciones académicas especializadas suelen concentrarse en aspectos puntuales de la producción de la escritora, dejando de lado rasgos estructurales fundamentales de la misma. Los únicos estudios integrales de la obra de Amelia Biagioni que se encuentran disponibles a la fecha son el de Cristina Piña (2005) y el recientemente publicado por Valeria Melchiorre (2014) como resultado de su Tesis Doctoral, aunque la producción científica de ambas no se limita a estos dos estudios, sino que se complementa con artículos, ensayos y prólogos previos. Tampoco puede soslayarse la valiosa contribución que suponen los escritos de Clelia Moure (2003, 2012), quien analiza en profundidad y con lucidez gran parte de la obra de Biagioni, trazando recorridos de lectura crítica que se sostienen en un análisis discursivo agudo y minucioso.
} 
barreras del discurso impuesto por las tendencias poéticas dominantes de su época en favor del desarrollo de una poesía que, atendiendo especialmente a la polisemia del término, podríamos calificar como alterna, tanto por su corrimiento de los ejes establecidos, como por su condición cambiante y nómade (Piña, “Amelia Biagioni: una poética”), la cual determina su singularidad y originalidad.

Si bien Biagioni se caracterizó por su bajo perfil, consecuente con una notoria preferencia por el alejamiento de los círculos literarios de prestigio, su gesto grandilocuente se encuentra, sin lugar a dudas, en su poesía. Como escritora, abogó por la casi nula exposición mediática, eligiendo mantenerse al margen de toda tradición literaria nacional en auge, lo cual convirtió su poesía en la expresión de una voz de caracteres únicos, imbuida de una potencia artística que volcaba en sus poemas mediante una labor sumamente minuciosa y obsesiva.

La trayectoria de la poeta, que abarca más de cinco décadas de intenso trabajo, evidencia, a simple vista, una cuestión para nada menor: su poética ${ }^{2}$, que en principio se adecua a ciertas convenciones genéricas y normas propias de la lírica clásica, alcanza su punto álgido a partir de la transgresión de dichas normas, de la puesta en cuestión de los principios de la tradición y de los códigos vigentes en su tiempo. En este sentido, Biagioni se presenta como una autora que legitima su obra "independientemente de las poéticas dominantes en la Argentina de la segunda mitad del siglo XX" (Melchiorre "A manera de" 6), transformándola en uno de los objetos de estudio más atractivos del panorama literario nacional de este período. Así, el gesto "rupturista" de Biagioni funciona en dos niveles. Por un

\footnotetext{
${ }^{2}$ Utilizamos el término según la segunda acepción que Víctor Zonana (2007) recupera de Tzvetan Todorov en su libro Poétique (1971). Zonana afirma, en un primer momento, que "la palabra poética significa actualmente muchas cosas" (15), para luego dedicarse a precisar el alcance del término en relación con la propuesta de Todorov. Según el teórico búlgaro, se pueden identificar tres vectores de sentido vinculados al término poética: “a) la poética en tanto teoría o reflexión acerca de la literatura o de fenómenos asociados a ella; b) en tanto conjunto de elecciones de un autor entre todas las posibilidades constructivas del objeto literario; c) en tanto conjunto de disposiciones o reglas prácticas adoptadas por determinada escuela literaria, reglas que permiten identificar su estilo" (Zonana 17). En este caso, cuando hablamos de la "poética de Biagioni" hacemos alusión al conjunto de elecciones temáticas, formales, procedimentales y discursivas de la escritora que, en su particular combinación, determinan el carácter de su obra y, por lo tanto, la singularidad de su producción.
} 
lado, en relación con su contexto, logra colocar su producción en una posición de desajuste con respecto a las posturas literarias prescriptivas imperantes, recurriendo "a tradiciones tan diversas como el Neorromanticismo cuarentista, la Vanguardia girondiana, el Romanticismo alemán y la poesía pura tal como la concibiera Mallarmé" (Melchiorre 7). Pero al mismo tiempo, la transformación se gesta en el seno de su propia labor poética: sus poemarios, lejos de seguir una trayectoria lineal, experimentan una transformación radical que se materializa con mayor fuerza en sus últimos tres libros. Su producción, en un principio tendiente a la autorreferencialidad del yo poético, volcada al verso en rima y al uso de los metros tradicionales y moldes estróficos convencionales, se transmuta de manera incesante hasta evidenciar lo que la palabra, una vez librada de sus investiduras denotativas, puede impulsar. En combinación con diversas técnicas de adjetivación, de juegos con el espacio en que se proyecta el lenguaje y usos de la materialidad sonora, los poemas se convierten en terrenos de lo plural, de lo no habitual, de lo desconcertante; en un muestrario de la potencialidad del lenguaje poético y de los horizontes hacia los cuales dicha potencialidad puede expandirse.

\section{Amelia Biagioni: itinerario(s) de una poesía singular.}

En sus primeros dos poemarios, Sonata de soledad (1954) y La llave (1957), Biagioni trabaja, como mencionábamos anteriormente, con recursos propios de un tipo de poesía de corte más tradicional, cercana en su despliegue retórico y en sus usos métricos a las pautas marcadas por las poéticas clásicas ${ }^{3}$. En cuanto a la estética, estos poemarios se caracterizan por su acentuada influencia neorromántica, reforzada por una instancia subjetiva femenina y autorreferencial, un yo lírico de corte autobiográfico que se relaciona estrechamente con la subjetividad de la poeta, dando lugar a una profunda exploración autorreflexiva e introspectiva. De este modo, Sonata de soledad pone en escena una voz poética

\footnotetext{
${ }^{3}$ Ver la clasificación propuesta en la Nota 2. En este caso, el término "poética" se correspondería con la tercera acepción aludida por Todorov.
} 
que hace emerger el mundo de la interioridad femenina con una fuerza abrumadora. Se trata de una individualidad imbuida de una sensibilidad perceptiva sumamente aguda y arraigada de manera firme en el terreno de la reflexión acerca de la sentimentalidad amorosa. Un "yo" que se define a partir de su relación con un "tú" que, tanto tácito como en presencia, ejerce una influencia constante sobre esa voz. Una melancolía musical sobrevuela con insistencia el poemario, que atraviesa diversas etapas: primero, el recuerdo de un ansia de amor en el que el yo lírico deposita sus esperanzas y anhelos; más adelante, el sufrimiento desgarrador provocado por el desarraigo amoroso y el alejamiento del ser amado - la desolación, la muerte y la ajenidad se transforman prácticamente en leiv motivs-; por último, un leve atisbo de esperanza: una posibilidad de supervivencia, de superación de la etapa de sufrimiento y de eventual recuperación. Probablemente sea el poema "Mis ojos" el que mejor condensa los distintos matices de la intensa vorágine sentimental que experimenta el yo poético a lo largo del poemario:

Antes de amar tenía

ojos de tierra seca.

Miraba inútilmente, como un ciego.

Una mañana pura, mis ojos, como flores, brotaron al brotar mi sentimiento.

Mientras amé en el gozo, mis ojos, deslumbrados, confundían la sangre con el sueño.

Mi amor llegó a la pena, llegó con ojos rotos.

Mirar tan sólo fue un desangramiento. 
Después entré a una muerte.

¡Oh, soledad! Cenizas, mis ojos, se volcaban para adentro

Hasta que fui a una isla

desnuda, la del aire.

Y mis ojos volaban sin recuerdos.

Un día volví al mundo, sonriendo con dos lágrimas, con los ojos profundos del regreso.

Volví con estos ojos intensamente humanos, ojos de Dios volcados sobre el tiempo
Ahora alumbro si miro, y miro como el agua, y todo lo que miro es compañero.

(Biagioni 113)

En este poema, la progresión emocional se sostiene en la proliferación de un lenguaje altamente metafórico, vinculado particularmente con lo que transmiten los ojos y la mirada. Los tercetos se configuran como pasajes poéticos en los que se plasman y condensan imágenes cargadas de lirismo. En un principio, el sujeto poético experimenta una ceguera figurada como consecuencia de su desconocimiento del sentimiento amoroso. Luego, la eclosión del goce producido por el éxtasis afectivo, en la que los ojos, antes incapaces de ver como los de un ciego, se transforman en flores que brotan junto con el sentimiento. Más adelante, los ojos se "rompen" y se "vuelcan para dentro" frente a la desilusión del amor 
CATEDRAL TOMADA: Revista literaria latinoamericana / Journal of Latin American Literary Criticism Amelia Biagioni o el imprevisible trayecto de una experiencia poética alterna

perdido. Esa etapa de quiebre emocional es seguida por un estado de suspensión y apatía, en el que "mis ojos volaban sin recuerdos", atravesando el duelo que implica el fracaso del desamor. Las últimas tres estrofas suponen la revitalización de unos ojos que poseen una doble naturaleza, en tanto son "intensamente humanos", pero a la vez "divinos". Finalmente, el poema se cierra con la fuerte presencia de una mirada iluminada, de unos ojos que se transforman en faros capaces de restablecer la armonía interior de la hablante, así como su vínculo con aquello que la rodea.

Es preciso mencionar que este desarrollo intimista que se da en el primer poemario de la autora, tiene su correlato en una dimensión espacial particular. Muchos de los poemas se encuentran enmarcados o atravesados por un ambiente netamente rural y pueblerino, como en el caso de "Noche y campo", "Noche y pueblo" o "Canción enlazada en trigo", o por uno marítimo y costero, como se observa en "Canción inmóvil", "Sumergida" o "Balada gris". Los dos ambientes, aunque disímiles en cuanto a algunos aspectos, presentan como rasgo común la abrumadora presencia de la naturaleza, en cuyo seno se despliega y desarrolla la intimidad del yo lírico.

En La llave, segundo poemario de Biagioni, se produce un desplazamiento del discurso poético desde el ámbito natural predominante en Sonata de soledad, al espacio netamente urbano de la gran ciudad, como queda evidenciado en la primera sección del poema "Diario": "Hoy he cambiado el pueblo/ por niebla de camino (...)/ La ciudad me abrazó/ con cemento infinito, / con idiomas y espaldas, / con circulares ruidos/ que arrastra, desollada" (Biagioni 161). Se trata de una modificación fundamental, puesto que, si bien el intimismo no es dejado de lado, cambia de signo radicalmente. La ciudad se muestra como potencial espacio de reencuentro del yo poético con su propio ser, según podemos apreciar en "Carta de Junio": "Sí lenta hermana, quiero aquí buscarme,/ en este laberinto sin reposo./ Iré por rascacielos, hasta hallarme/ moviendo un viento fabuloso" (Biagioni 164). Como parte de este proceso, se desarrolla un vínculo especial entre el yo poético y aquellos objetos, emplazamientos físicos y atmósferas que lo 
rodean. Dicha proximidad latente, supone una profunda relación de familiaridad entre la hablante lírica y los sitios y elementos urbanos, como si éstos pudiesen formar parte de ella, influyendo, incluso, en su estado anímico. En esta línea se encuentran los poemas pertenecientes a Habitación 114, una de las secciones del poemario en la que aparecen poemas como "Canción para una mesa de luz", "Canción para un ropero de hotel" o "Canción para una cama de hotel" (como puede notarse a partir de los títulos, la vocación musical del poemario anterior continúa presente), en alternancia con otros poemas a modo de cartas o fragmentos de diarios íntimos "urbanos". En estos casos, el vínculo al que hacíamos alusión previamente queda evidenciado en la propia gramaticalidad del discurso, puesto que el yo lírico refiere -y hasta apela- a los objetos utilizando la segunda persona del singular del modo indicativo (en lugar de emplear la tercera persona), como puede apreciarse en los versos citados a continuación: "Frío pedazo de árbol/ haz que se calmen mis sienes/ en tu mármol" (Biagioni 183 [en alusión a la mesa de luz]); "Nunca serás de nadie/ total, definitiva;/ pero todo lo humano/ sabes, blanda, pasiva" (Biagioni 187 [en alusión a la cama de hotel]).

No obstante la búsqueda emprendida, el desarraigo y la nostalgia del yo lírico se acentúan -"Rodando en gasolinas y monedas/ mi soledad es puro sobresalto" (Biagioni 164)-, aunque no parece haber una actitud de resistencia frente a esta situación, sino una resignada admisión de la conflictiva realidad emocional que se experimenta: "Ando de rostro en rostro, ya perdida/ de corazón, de ser en todo ser./ Subo por otra calle de la vida, / y recomienzo a suceder" (Biagioni 166). La frustración encuentra como único alivio la insoslayable confianza en una instancia superior divina (las referencias bíblicas son numerosas y Dios -comprendido en un sentido católico, es decir, como entidad antropomórfica creadora ultraterrena- aparece mencionado en una decena de oportunidades), así como en un atisbo de comunión con la naturaleza/ universo, principios ya presentes en el poemario anterior que, como nota Valeria Melchiorre (“A manera de” 8), serán recuperados en los libros posteriores, y que, además, brindan al sujeto poético un sostén en el que reafirmarse. Según Cristina Piña, 
este "Dios tradicionalmente concebido como instancia trascendente y encarnación del Bien y la unidad (...) funciona como garantía de la sustancialidad del yo (...) como refugio ante la crisis producida por el desarraigo" ("Amelia Biagioni: una poética" 25). Asimismo, la poesía se muestra como una suerte de instancia reparadora, como canto sanador que inspira la catarsis de un espíritu contrariado, y que conduce a su expiación mediante cierta evasión de tono romántico, tal y como se muestra en la estrofa final del último poema del libro, "Bosquejo del último canto": "Ya no sucedo. Soy, / simplemente, y el aire no me roza. / Soy sin nostalgia... Estoy/ sin fin, amando, amada, luminosa...” (Biagioni 226).

Como hemos podido apreciar, un amplio conjunto de rasgos temáticos ubican esta primera etapa de la poesía de Biagioni en un terreno en el que el yo aparece como eje ordenador del poema, al tiempo que la subjetividad invade el discurso poético. Si bien la conexión entre los poemarios es manifiesta, y ciertas continuidades que funcionan a modo de ejes estructurales ${ }^{4}$ son, a su vez, innegables, la escritura de Biagioni comienza a evidenciar notorias modificaciones que se materializan a partir de su tercer libro, El humo (1967), poemario de transición que, como indican Piña ("Amelia Biagioni: una poética") y Moure ("Yo persigo"), anticipa muchas de las variantes formales y estilísticas que podrán apreciarse plenamente desde el cuarto libro. En primer lugar, la subjetividad sufre una mutación favorecida por la diseminación (Derrida) y el estallido (Moure "Voces y materias") del lenguaje, dando lugar a un yo que rompe con los esquemas tradicionales de una lírica en la que el sujeto poético domina el lenguaje, y no a la inversa. En este sentido, coincidimos con Cristina Piña en cuanto a que El humo presenta las "primeras rupturas radicales, tanto en el concepto de subjetividad como algo dado, cerrado sobre sí y existente al margen

\footnotetext{
${ }^{4}$ Coincidimos con Valeria Melchiorre en que algunos rasgos funcionan como constantes en la poesía de Biagioni: "la isotopía de lo musical y la identificación de la poesía con el canto; el vínculo que se instaura entre la subjetividad y la naturaleza-universo; y, sobre todo, la conciencia de lo poético como condición inherente de la identidad" (8), a los que podríamos agregar la presencia del componente religioso y la recuperación de la tradición, ya sea para inscribirse en ella, o para subvertirla.
} 
de la escritura, como en los aspectos formales y en el vínculo con el lenguaje" (Piña "Amelia Biagioni: una poética" 26). La rima deja de ser un elemento fundamental para aparecer esporádicamente; las enumeraciones asindéticas comienzan a poblar los poemas, y los encadenamientos sintagmáticos pasan a prescindir de las reglas gramaticales y lingüísticas convencionales, generando efectos vinculados con el orden de lo rítmico y lo sonoro. Asimismo, las estrofas, entendidas como unidades métricas de sentido, dejan paso a la libre disposición de los versos en la hoja, y la distribución de las palabras en la página se resignifica a partir de la utilización productiva de los espacios en blanco. La lógica racional que sobrevolaba los primeros dos poemarios, tambalea frente a una explosión polisémica de sentidos que se disparan hacia múltiples direcciones, obturando la comprensión unívoca del discurso poético y favoreciendo una diseminación que parece sostenerse en los juegos contrastivos de palabras, el puro ritmo, la cadencia acumulativa y la expansión de cadenas de versos ad infinitum:

\author{
$\mathrm{Y}$ ardiendo en otro tiempo \\ acuden \\ las lenguas bífidas rosadas \\ carmesíes, \\ las sibilas convulsas \\ las mil \\ ardiendo guay \\ consumen, \\ las lenguas miserere \\ las euménides púrpuras \\ consuman \\ ardiendo amén, \\ las lenguas encarnadas \\ las perversas y santas inocentes \\ prosiguen \\ ardiendo azules escarlatas
}




\section{CATEDRAL Tomada: Revista literaria latinoamericana / Journal of Latin American Literary Criticism}

Amelia Biagioni o el imprevisible trayecto de una experiencia poética alterna

mentidas hasta el gris

hasta el sangre verídicas

ardiendo

igualando

obedecen

las lenguas serviciales (...)

(Biagioni 266)

Como puede observarse, los versos "no se dejan apresar en un sentido definitivo y único sino que apuntan a diversos sentidos, incluso contradictorios" (De Peretti 159). Algunos ejemplos: las distintas "lenguas" que aparecen a lo largo del poema generan un extrañamiento singular derivado de la plurivocidad de sentidos que surge a partir de su uso reiterado, pero cambiante a la vez; la insistencia en la repetición del gerundio "ardiendo" refuerza la carga semántica del sustantivo "lenguas", así como su connotación religiosa (es insoslayable la remisión a las "lenguas de fuego" que descienden sobre los apóstoles en el Nuevo Testamento); los sintagmas "consuman"/ "consumen" engendran un abanico de sentidos producto del juego homofónico que se establece entre ellos; las lenguas "encarnadas" (nuevamente encontramos una remisión a la religión católica que, en este caso, podría aludir al cuerpo de Jesús en tanto Dios encarnado) aparecen simultáneamente como "perversas y santas inocentes", lo cual, lejos de suponer una contradicción, implica una peculiaridad altamente productiva, sobre todo si tenemos en cuenta la noción de "negatividad” de Julia Kristeva, según la cual "lejos de excluir dos términos (categorías) que se oponen, el significado poético los engloba en una ambivalencia, en una reunión no sintética" ("Poesía y negatividad" 63) ${ }^{5}$. Dicha productividad se deriva, a su vez, de la falta de concordancia gramatical entre los términos y la imposibilidad de asignarles roles

\footnotetext{
${ }^{5}$ Para Kristeva, el lenguaje poético permite la afirmación y la negación recíprocas y simultáneas, desarticulando las dicotomías y la oposición de pares binarios propia de la "lógica del habla", en la que un elemento léxico posee carga semántica positiva y el otro negativa, con lo cual un término se privilegia sobre el otro, que termina siendo excluido (61).
} 
sintácticos fijos a los sintagmas que forman las cadenas oracionales, también confusas desde el punto de vista de la "lógica del habla", como la denomina Kristeva (61). Esto se debe, según la autora, a que se encuentra operando una lógica completamente distinta, una lógica-otra: la del "extra-habla" -propia del lenguaje poético- que "reúne simultáneamente lo positivo y lo negativo, lo que existe para el habla y lo que es no-existente para ella" (61).

Asimismo, los pilares y certezas en los que se sostiene el yo poético en los primeros poemarios -la presencia de Dios, la poesía como lenguaje que permite vehiculizar el intimismo, la univocidad de la identidad- caen y son reemplazados por la inquietud, la desorientación y la incertidumbre. Esta desarticulación de la instancia subjetiva centrada en sí misma puede observarse de manera clara en algunas personificaciones que asume el yo poético (la llovizna, el humo) y en su eventual transmutación en distintos seres (la paloma, la mariposa). Como consecuencia, se produce una fractura del yo, el descentramiento de una subjetividad que pierde progresivamente su unidad identitaria. En este sentido, resulta paradigmático el poema "Cada día, cada noche", el cual transcribimos a continuación, puesto que sintetiza de manera clara este vaciamiento y dualidad del ser- no ser que experimenta el yo poético (la cursiva es nuestra):

\section{Cada día}

me levanto sin nombre,

y en la nuca

una sombra

tenaz, ajena, a filo,

me acusa desde siempre;

y la culpa

total, indescifrable,

entra, me usurpa,

no sé quién soy, me oculto, huyo

y me pierdo extranjera.

Hasta sentir, 


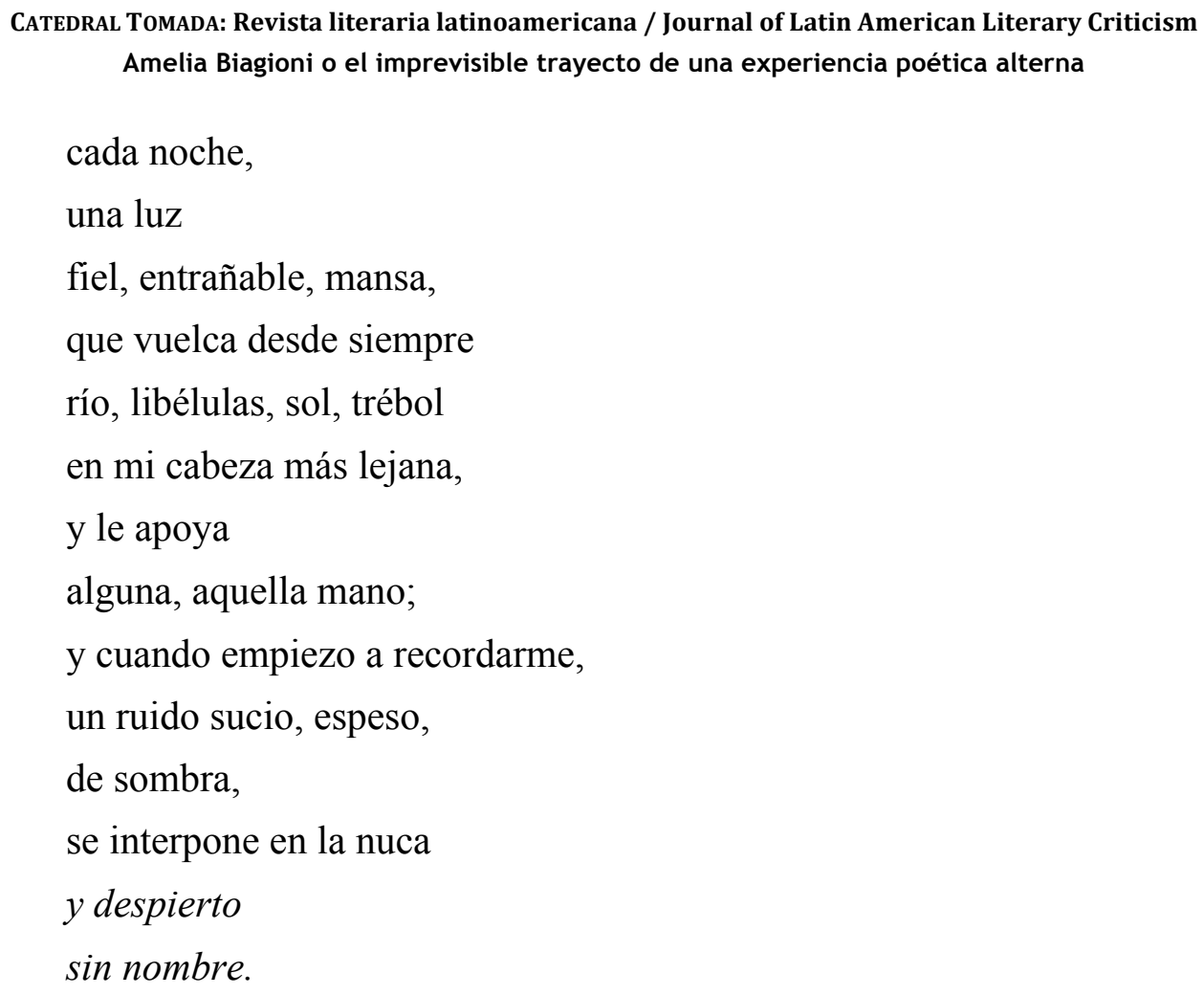

La cosmovisión religiosa, en tanto rectora de la percepción del sujeto poético, también encuentra un punto de inflexión a partir de El humo. La instancia divina no desaparece, pero ya no se muestracomo sinónimo de garantía o refugio, sino que es carnavalizada, deconstruida y puesta en cuestionamiento, correlato de una progresiva desacralización de la figura de Dios, quien es presentado como un prestidigitador todopoderoso del destino del hombre: "Si no quieres cerrar tu juego/ de ocioso dios y cancelarme,/ imagíname de una vez/ en el aire final, sin aire / Quítame al menos la obsesión / de tu desdén, de mi destino”, y, más adelante, "Tu piedad y tu magia admitan/ que mi canción de cuna suene" (Biagioni 281). Es evidente que este Dios difiere notablemente del que aparece en Sonata de soledad y La llave: se trata de un ser de actitud lúdica, calificado como "estéril" y "ocioso", que parece jugar con la vida de los hombres con una actitud de despojo y crueldad, y al que, además, se le atribuyen cualidades mágicas, convirtiéndolo en una entidad sobrenatural de naturaleza pagana. Incluso el 
propio nombre de Dios aparecerá despojado de su connotación divina al transformarse en un sustantivo común que aparecerá escrito con minúscula en repetidas ocasiones. Otro gesto de singular importancia en relación con este aspecto lo constituye el poema que da inicio a El humo, en el cual se ensaya una suerte de canto de alabanza al infierno, ya no comprendido como espacio de tormento y sufrimiento, sino como “(...) el recinto / donde encuentro, / retenidos por el ojo y el fuego / los nombres y las formas / de la dicha” (Biagioni 229).

Este camino de descentramientos y heterogeneidades, iniciado por Amelia Biagioni en El humo se profundiza en Las cacerías (1976), poemario que abre la puerta de manera definitiva a una comprensión diferente de su concepción poética y de su escritura. El título del poemario prefigura una dinámica de fuga y persecución, de intercambios e inversiones de roles en la que el cazador deviene víctima (y viceversa), y a partir de la cual el movimiento se transforma en el motor fundamental de la poesía: "mis actos/me mostraron/ que el universo es un oscuro claro andante bosque/ donde todo movimiento es cacería" (Biagioni 361). El sentido fluye a través de versos que se desplazan con soltura y los poemas dejan de organizarse necesariamente en torno a unidades estróficas para dejar paso al libre discurrir de la palabra poética:

En su eje de sol de rey de único viene girando

$$
\text { es él }
$$

y me manda sus ojos

y subo y soy el dueño y mano luna

es él

girando

y derramo su nombre

es él es él

y me persigue y no me alcanza

es él

y lo persigo y no lo alcanzo 


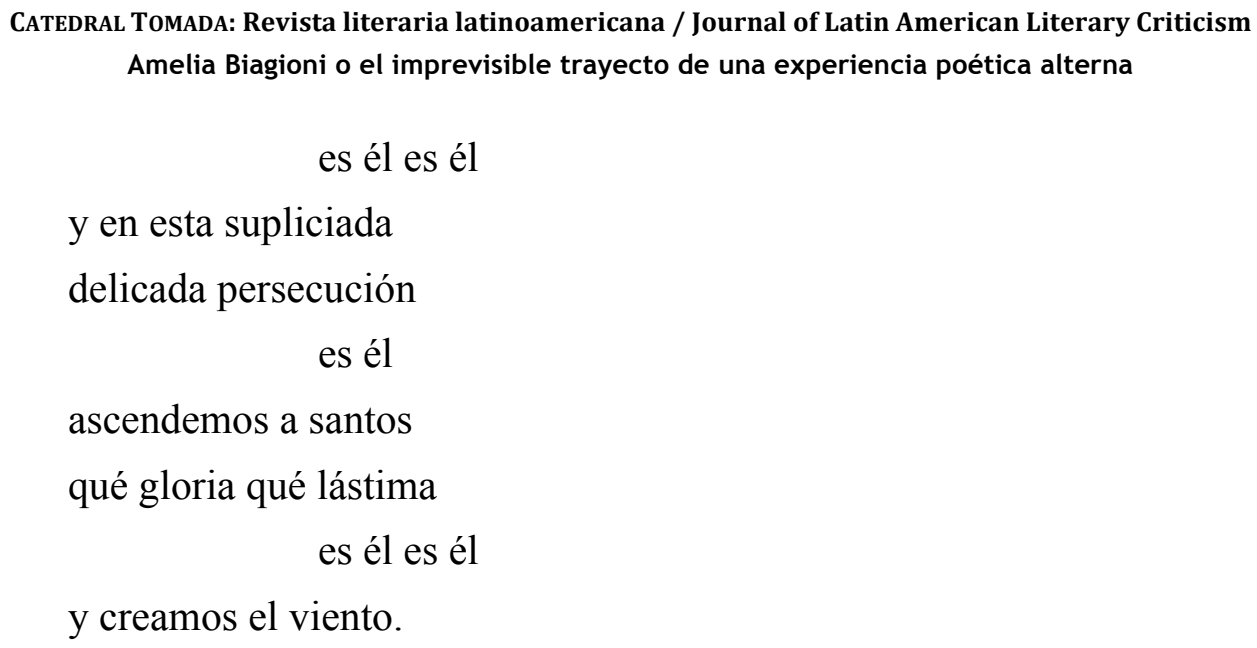

(Biagioni 333)

El poema anterior, titulado "Guarda en ánfora", presenta una serie de aspectos formales que dan cuenta de la modificación sustancial que opera en el poemario. En primer lugar, la concatenación y acumulación de términos mediante el despliegue de estructuras sintácticas cuya recursividad podría ser considerada como redundante bajo los parámetros de una "lógica del habla", pero que en este caso suscita una multiplicidad de sentidos simultáneos, tal como sucede en el primer verso: "En su eje de sol de rey de único". También resulta significativa la distribución irregular de los espacios gráficos y de los blancos de la hoja: nótese el desplazamiento hacia la derecha de los versos sueltos conformados por el sintagma oracional "es él", que aparecen como interpolaciones de otra voz en el poema. En este sentido, es importante destacar la relevancia de la polisemia del pronombre personal en tercera persona singular ("éll"), que, si bien adquiere un peso particular en relación con la religión, puede ser interpretado en más de un sentido. Una primera lectura nos remite al Dios cristiano, pero desacralizado: "Él”, con mayúscula, refiere en la cultura católica al creador, y en este caso, se encuentra escrito con minúscula. En sintonía con la línea religiosa, la reiterada aparición del sintagma en cuestión, tanto como su alternancia en forma duplicada, recuerda a la letanía, con lo cual permitiría pensar el poema como una suerte de Salmo, remitiéndonos, una vez más, a la poesía comprendida como canto. No obstante, el pronombre no necesariamente refiere a Dios, y el poema no explicita 
dicha relación en ningún momento, por lo que también permite pensar otras posibilidades. Así, podría estar aludiendo a un cazador -si tenemos en cuenta la insistencia de la idea de la persecución en el poema, reforzada por el vertiginoso ritmo de lectura que genera la ausencia de signos de puntuación-, a otra deidad o, incluso, a un referente/individuo completamente ajeno. Estas ambigüedades son las que garantizan el engendramiento y la circulación de múltiples sentidos que no sólo aparecen como opciones disponibles dentro de un paradigma, sino que conviven y coexisten en simultaneidad.

En Las cacerías la subjetividad alcanza un grado de pluralización aún más extremo que en el poemario anterior. El sujeto poético, despojado del punto de anclaje que ofrecían las instancias de refugio en los primeros poemarios, así como de un lenguaje referencial y "transmisor" de significados más o menos concretos, se transmuta en diversas identidades. Comienza, así, a alternarse la impersonalidad (en poemas como "Sucede a veces", "Chacarita" o "Recoleta") con la ajenidad de un yo desarticulado y múltiple que puede asumir diversas personalidades como la del apóstol Pablo en "Laguna Salvia-Tercer miliario-Año 67" o la de "El otro Hemingway", e incluso con voces anónimas como las que aparecen en los seis breves poemas que conforman la sección denominada "Decir". En la primera parte del poemario se produce, además, una metamorfosis radical de la subjetividad unitaria a partir de la delegación de la instancia enunciativa en la voz de diversas criaturas como la hormiga, la rana y el tigre ${ }^{6}$, mientras que, llegando al final, esa transfiguración subjetiva se traduce en la adopción de roles como el de una "señalada", una fugitiva y una partiquina, profundizando un procedimiento ya iniciado en El humo.

Las jerarquías son anuladas y reemplazadas por una dinámica de persecución infinita en la que los límites tienden a ser eliminados y la poesía se convierte en una incesante e incansable búsqueda: "Lleva en el ojo un cazador

\footnotetext{
${ }^{6}$ Para un análisis pormenorizado y detallado del despliegue, funcionamiento e implicancias de estas "voces", remitimos al trabajo de Moure (2003), quien realiza un rastreo y desglose discursivo minuciosos.
} 
CATEDRAL TOMADA: Revista literaria latinoamericana / Journal of Latin American Literary Criticism

Amelia Biagioni o el imprevisible trayecto de una experiencia poética alterna

que acecha/ y este en el ojo un cazador que acecha/ y este en el ojo un cazador que acecha/ y así hasta las tinieblas" (Biagioni 383). Se trata de una escritura en permanente avance y retroceso, una cacería perpetua y eternamente inconclusa, que no acusa principio ni fin, sino el corrimiento de las fronteras de una poesíauniverso en constante expansión. El poemario genera, de este modo, una dinámica poética cosmológica en la que la naturaleza, los seres vivos y el yo poético (en sus diversas manifestaciones) se determinan de manera mutua y se funden en un único acto creador: la poesía. Esta vitalidad cósmica-artística que impregna el poemario, así como el juego de espejos e inserciones infinitas, aparecen reflejados de manera clara en "El todo", título de por sí elocuente que, por otra parte, nos remite otra vez al ámbito de la religión:

Porque un corpúsculo

tiene en pasión y acción

el volumen del cielo

y porque el tiempo avanza retrocediendo

y porque sólo hay pan hambriento vertiginoso

y porque sólo ves con límites

puedes decir simplificando:

El todo es un instante o ascenso

con un amor o víctima primera

de otro

consumido

por la víctima

de un otro

devorado

por la víctima

de un otro y siempre así

feliz y atroz

y siempre diferente, 
hasta un amor o víctima final

que es la primera

dentro de otro universo.

(Biagioni 401)

Como se ve en este fragmento, la lógica de la devoración, semánticamente vinculada con la práctica de la caza, se expande en una vorágine de inserciones, en un movimiento de "consumición" (deglución) que, al igual que sucedía en el fragmento de "El humo" citado más arriba, es también "consumación" de la cacería y del acecho, es decir, un discurrir de orden inclusivo y, por lo tanto, absolutamente desjerarquizante: "queda claro que cualquier principio tanto jerárquico como excluyente ha desaparecido a favor de uno inclusivo, según el cual los elementos se vinculan por coordinación rizomática de heterogeneidades, según la ley del y ... y... y..." (Piña "Amelia Biagioni: una poética” 39). De este modo, principio y fin dejan de ser instancias rectoras fijas para pasar a ser simples eslabones en una cadena infinita de sentidos, tal y como los poemas funcionan como eslabones en el poemario y el poemario como eslabón en la totalidad de la producción de la autora. Esta ausencia de inicio y final / origen y desenlace, ya observada en poemas como "Concéntricos", refuerza, como señala Moure ${ }^{7}$ ("Voces" 127), una idea de circularidad también presente en otros poemas como "Cazador en trance", dinamizando la circulación de sentidos dentro de la red paragramática (Kristeva "La palabra" 239) que constituye el poema. Como resultado, se borronean los roles, se trascienden los límites y se quiebran las dicotomías, puesto que, según observa Cristina Piña "si los términos contradictorios final-primero, feliz-atroz, amor-víctima han dejado de oponerse, la reversibilidad entre cazador y víctima, uno y otro, pasado y presente, adentro y afuera, vida y muerte, es absoluta" (39). Creación, universo(s), poema(s), escritura expansiva, movimiento, cacería y devoración se entrelazan, así, en un

\footnotetext{
${ }^{7}$ La autora incluso afirma que la propia estructura del poemario es concéntrica y se organiza en torno a cinco poemas: "Gestalt", "Cazador en trance", "Bosque", "El todo" y "Mensaje del lunauta", siendo "Bosque" el que funciona como eje central (Moure 126)
} 
CATEDRAL TOMADA: Revista literaria latinoamericana / Journal of Latin American Literary Criticism Amelia Biagioni o el imprevisible trayecto de una experiencia poética alterna

conglomerado discursivo de caracteres múltiples e irreductibles, cuyos efectos se proyectarán (como veremos más adelante y, en cierta medida, retrospectivamente) en los dos poemarios siguientes.

El cuarto libro de poemas de Amelia Biagioni, Estaciones de Van Gogh (1984), combina la producción de la propia autora con fragmentos de la correspondencia que Vincent Van Gogh envió a su hermano Théo, y constituye un claro ejemplo de cómo la literatura puede ser entendida como práctica poética intertextual que transgrede la normatividad de la lengua, dando lugar, tal y como afirma el filósofo Jacques Derrida, al "juego de la huella que es huella de otra huella... Red infinita de significantes" (De Peretti 165). La obra se encuentra dividida en cuatro secciones (las "estaciones" a las que hace referencia el título: "Zundert-París", “Arles", "Saint- Rémy” y "Auvers-sur-Oise”, respectivamente) y se estructura en torno al diálogo que se establece entre los poemas propiamente dichos y los extractos de las cartas de Van Gogh a Théo, relación dialéctica que no sólo se produce mediante una identificación correlativa e inmediata, sino también entre fragmentos y poemas pertenecientes a distintas estaciones. Por este motivo, Estaciones de Van Gogh puede ser considerado un poemario-rizoma, en tanto se encuentra atravesado por relaciones textuales complejas e inesperadas que mixturan la escritura con otras formas del arte. Este entrecruzamiento es posible si tenemos en cuenta que, como afirman Deleuze y Guattari, "en un rizoma (...) cada rasgo no remite necesariamente a un rasgo lingüístico: eslabones semióticos de todas las naturalezas son conectados a formas de codificación muy diversas" ( Deleuze y Guattari 16). En este sentido, son reiteradas, por ejemplo, las referencias a una serie de tópicos e ideas acerca del arte y su puesta en práctica, la producción pictórica per se y el rol del artista. En términos generales, las disquisiciones sobre la potencia y la capacidad artística creadora, el acto de pintar y las dificultades que este conlleva son cuestiones que, extraídas de los fragmentos, se interpolan con insistencia en los poemas. De esta manera, el poemario combina la escritura con elementos pertenecientes al orden de lo 
pictórico, generando una correspondencia entre ambos planos que no sólo se da en términos temáticos, sino también, y fundamentalmente, discursivos.

Un tercer elemento se suma a esta heterogénea trama textual: la musicalidad. La rítmica de los versos acompaña muchas veces su desplazamiento en la hoja, y su disposición no lineal (que se verá radicalmente acentuada en Región de fugas) genera un efecto de lectura que puede asociarse tanto al devenir musical propio de una partitura, como al movimiento del pincel en un lienzo. Así, el poemario logra configurarse como espacio de multiplicidades en el que confluyen elementos y procedimientos vinculados a la tríada pintura - música escritura, conjugando de manera armónica y consonante tres órdenes perceptuales divergentes que interactúan y dialogan entre sí.

Una de las estrategias a partir de las cuales la estructura rítmica se plasma en los poemas es la repetición sonora. En el poema "2" perteneciente a "Arles", posiblemente el más representativo del conjunto, el trabajo con la diferencial significante fónica, en términos de Julia Kristeva ("Poesía" 121), es notorio en los primeros cuatro versos, fundamentalmente por la reiteración de los sonidos "S", "O" y "N", que pluralizan los efectos de sentido en el poema:

Con toques fusas gritos y cadencias

que se combaten y se abrazan

con acordes contrapuntos y armónicos

agónicos violantes o felices

pinta el concierto salvaje alado hermoso doloroso

la blanca verde púrpura negra música

sólo amarilla de la humana vida

que suena en todo espacio padecido

en todo rastro o reino

del pensamiento el ansia el acto.

Pinta la música encarnada

la música vidente

la música de la verdad 
CATEDRAL TOMADA: Revista literaria latinoamericana / Journal of Latin American Literary Criticism Amelia Biagioni o el imprevisible trayecto de una experiencia poética alterna

(Biagioni 463)

La disposición gráfica de los versos también posee una importancia crucial. En general, se despliegan de manera irregular, no todos agrupados hacia la izquierda, sino en un vaivén que parece remitir a los trazos de una brocha, lo cual supone la transposición de pinceladas horizontales al espacio gráfico del papel. En relación con este modo de distribución, también es pertinente notar la presencia de un campo semántico relacionado con la música ("fusas", “cadencias", “acordes", “contrapuntos”, “armónicos”) asociado, una vez más, a un procedimiento de transposición que, en este caso, sugiere la evocación de un ritmo musical.

Por otra parte, y recuperando un eje que hemos desarrollado anteriormente, no podemos dejar de notar la problematización de la subjetividad en el poemario, en tanto se despliega en tres "niveles": una primera persona que aparece como "biógrafo" de Van Gogh; otra que se metamorfosea con la figura de Vincent, emulando su voz en los poemas titulados según los nombres de sus pinturas más famosas; y, por último, la proyección autobiográfica en el poemario de la propia Biagioni, quien deja entrever su identificación con las peripecias que vivió el holandés.

Con Región de fugas (1995), último libro publicado en vida por Biagioni, la autora lleva a un extremo la práctica de la multiplicidad poética en términos de Deleuze y Guattari (18). Los poemas alcanzan un nivel de heterogeneidad tal, que los significados, frente a la ausencia del sustento biunívoco del signo lingüístico, llegan a desvanecerse por completo. Este resultado es alcanzado a partir de un cuidadoso trabajo con el lenguaje que, por ejemplo, abunda en la creación de neologismos mediante la combinación de lexemas morfológicamente divergentes, así como en la adjunción de términos que se suceden de manera acumulativa y dislocan toda posibilidad de deducir/ reducir a un único sentido la palabra poética. Esta polisemia radical es anunciada ya desde el título, puesto que las fugas en 
cuestión aluden tanto a su carácter de "composición musical", como al "momento de mayor fuerza o intensidad de una acción" - según una de las acepciones del diccionario de la RAE (2001) -, o incluso a la interpretación que Deleuze y Guattari hacen del término cuando teorizan acerca de las "líneas de fuga" del rizoma, sin ser éstas las únicas posibilidades, sino sólo algunas de ellas. Las referencias intertextuales también juegan un rol fundamental, tanto explícita como implícitamente. La intromisión de las bastardillas, y la consecuente alternancia de tipografias que generan en los poemas, se convierte en un elemento fundamental, puesto que, además de remitir a otros discursos generando una vorágine polifónica de ecos y resonancias constantes, su intercalación en los poemas los hace, en muchos casos, devenir reescrituras. Y no sólo reescrituras de carácter "extranjero", sino también intratextuales, como nota Cristina Piña ("Amelia Biagioni: una poética” 77), ya que las alusiones y reminiscencias a sus dos poemarios anteriores son reiteradas.

El yo lírico vuelve a sufrir un descentramiento absoluto en este poemario, transformándose alternativamente en un ser/ no-ser que experimenta el extrañamiento y la enajenación propios de una subjetividad nómade y plural. El borramiento y la anulación conviven con la mutación y el movimiento; afirmación y negación del sujeto se suceden indistintamente y de manera simultánea, produciendo un estado de fuga también en el plano de la enunciación. En cuanto al lenguaje y su disposición material, es notoria la acentuación del trabajo con la distribución espacial de los versos, como sucede en el siguiente fragmento de "Arpa":

$$
\begin{aligned}
& \text { Y así - mujer que gimecanta- vibro } \\
& \text { en el corto jardín o intermezzo, } \\
& \text { por mis custodias cómplices rasgueada } \\
& \text { rumbo a } \\
& \text { despavoridos } \\
& \text { y roídos }
\end{aligned}
$$




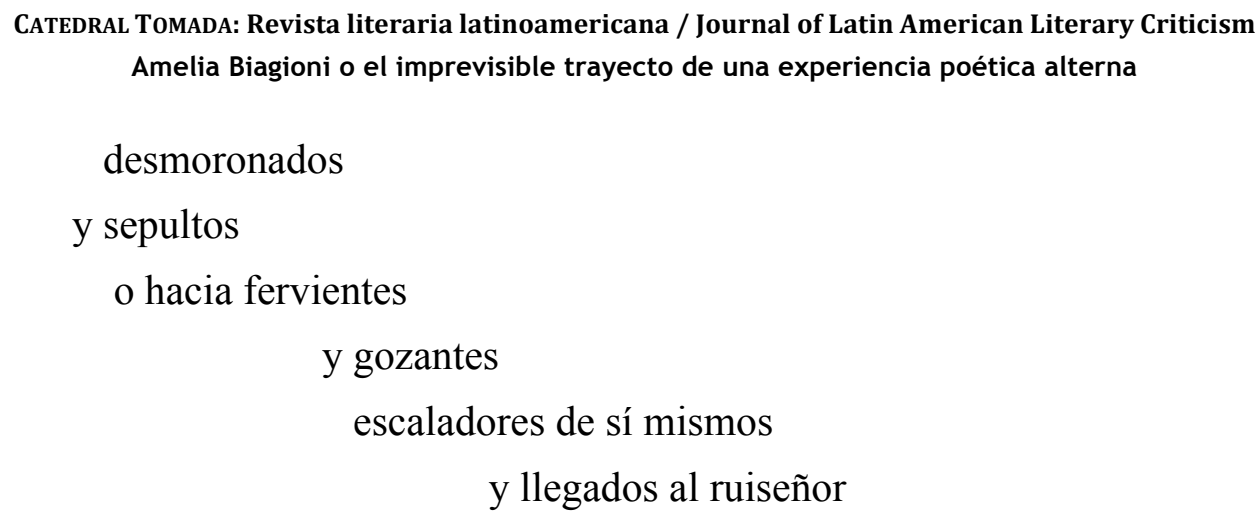

hasta que otra sinfonía me engulle.

(Biagioni 523)

Nótese de qué manera los versos se quiebran paulatinamente produciendo desplazamientos escalonados de izquierda a derecha y viceversa, movimientos que acompañan el engendramiento de un zigzag vertiginoso de sentido(s): cuanto más a la izquierda se trasladan los términos, su valencia semántica negativa se acentúa, mientras que a medida que avanzan hacia la derecha, la valoración positiva se incrementa. Finalmente, se produce un repliegue total del último verso hacia la izquierda, al margen de la hoja, lo cual puede leerse como un nuevo comienzo, interpretación respaldada por la significación que el propio verso transmite al referir a esa "otra sinfonía" que "engulle" al sujeto poético, dándole la posibilidad de un re-inicio y remitiendo, a su vez, a la poesía como música (al igual que en los poemarios anteriores) y como devoración (tal y como era comprendida en Las cacerías). El espacio de la hoja se convierte en un recurso activo del poema, puesto que el posicionamiento de los versos, en sintonía directa con la carga significante de los términos, favorece la infinitización de sentidos. Otro ejemplo de similares características aparece en el poema "Noche entreabierta":

Veo en la oscuridad un vertical fulgir

$$
\begin{gathered}
\text { una } \\
\text { axial } \\
\text { abismal }
\end{gathered}
$$




$$
\begin{gathered}
\text { pensadora } \\
\text { sonriente } \\
\text { enamorada } \\
\text { mirilla } \\
\text { de la } \\
\text { Luz }
\end{gathered}
$$

(Biagioni 573)

En este caso, el bloque inmediatamente posterior al primero de los versos, alineado en forma perpendicular al término "vertical" (del cual brotan y se desprenden los demás), funciona como una materialización gráfica del "fulgir", que es, a su vez, "mirilla de la Luz", en tanto puede notarse una similitud de forma entre el contorno que dibuja la disposición de los versos en el fragmento, y el haz de luz que penetra en el ojo a través de la mirilla de una puerta. De este modo, como apunta Valeria Melchiorre, "la forma caligramática se consolida en el caligrama propiamente dicho" ("Amelia Biagioni: la "ex-centricidad" 298). Asimismo, este conjunto de versos se dispone de acuerdo con una simetría "axial" que refuerza y explota gráficamente la carga semántica de dicho término. La explotación del elemento léxico también puede apreciarse en la escenificación del par oscuridad-luz, cuyo contraste fundamental no sólo involucra una ambivalencia altamente productiva en términos poéticos sino que, además, alude al plano de lo religioso, lectura que posee su clave interpretativa en la utilización del término "luz" con mayúscula.

Pero probablemente sea la técnica empleada en la última sección del poemario (también titulada "Región de fugas") la que mayor incidencia posee dentro del conjunto. Nos referimos a lo que Cristina Piña dio en llamar "principio de lectura reversible" (78), y que consiste en un dislocamiento de la linealidad de la palabra poética, una reversión del régimen de lectura tradicional concebido de arriba hacia abajo y de izquierda a derecha. El recorrido de lectura se transforma en una experiencia multidireccional y paragramática (Kristeva "Poesía" 114) que habilita un itinerario imprevisible y cambiante, fundado en avances, retrocesos, 
CATEDRAL TOMADA: Revista literaria latinoamericana / Journal of Latin American Literary Criticism Amelia Biagioni o el imprevisible trayecto de una experiencia poética alterna

alternancias y saltos. De esta manera, se hacen posibles lecturas de derecha a izquierda y de abajo hacia arriba, las cuales pueden progresar siguiendo las dos líneas de columnas paralelas en las que se pliega el poema, o trasladándose de un bloque estrófico a otro mediante movimientos en zigzag. Como consecuencia, los límites del/ los poema/s, se hacen difusos, puesto que las posibilidades de asociación/ disociación son múltiples. El poema comprendido como unidad textual cerrada y claramente delimitada, deja paso a un conjunto de complejas relaciones -rizomáticas en lugar de consecutivas- entre diversos fragmentos:

1

Vista desde el

Big Bang

vivida desde el

bosque

de los nombres,

la pensadora

carmesí

persecución,

la humanidad,

es fugitiva:

todos sus pasos

-míos-

sus actos -míos-

todos

hasta los más

sagrados

sembrados

y apresantes

atravesando

límites 


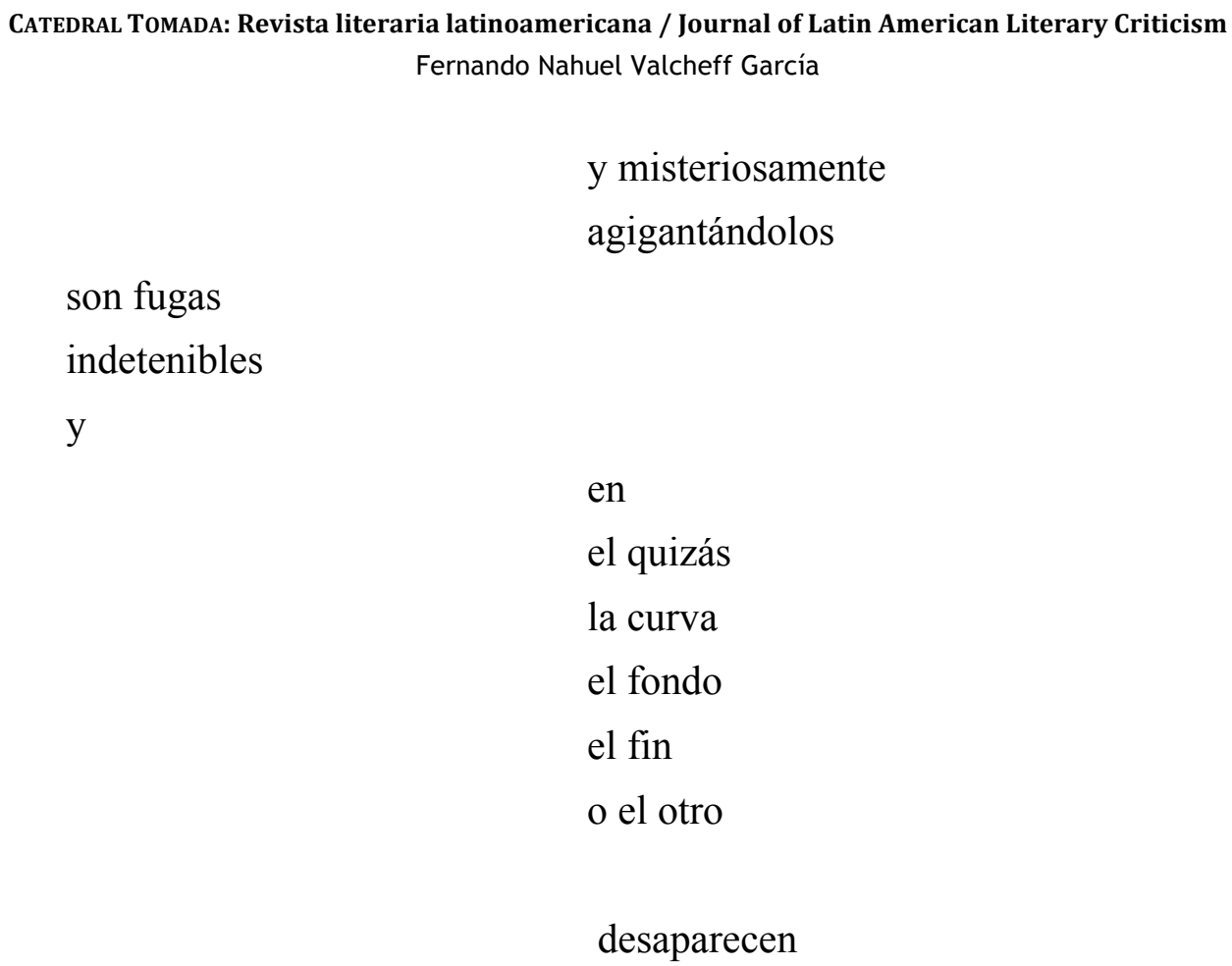

recurrentes.

(Biagioni 577-578)

La sección "Región de fugas" puede ser interpretada, entonces, como un único poema dividido en tres partes, o como tres poemas independientes que a su vez contienen sucesivos poemas que podrán leerse secuencialmente, en paralelo y/o en simultáneo. Este recurso, con todas sus variantes, lleva a un nuevo extremo la heterogeneidad que se venía gestando en los libros anteriores, dando lugar a una explosión de sentidos que se vinculan con núcleos temáticos de fuerte connotación religiosa, como la creación, la trascendencia, el universo y la humanidad (explotados de manera altamente productiva en Las cacerías), y resignificando dos de los principios medulares de su poesía: el movimiento y la fuga, en su polisémica interpretación que remite, simultáneamente, al desplazamiento y a la música. 
CATEDRAL TOMADA: Revista literaria latinoamericana / Journal of Latin American Literary Criticism Amelia Biagioni o el imprevisible trayecto de una experiencia poética alterna

\section{Fin del recorrido: algunas consideraciones a modo de cierre}

Con este trabajo, hemos intentado dar cuenta de algunas de las aristas principales de la poesía de Amelia Biagioni, prestando especial atención a cierto conjunto de factores temáticos y rasgos formales y discursivos sobresalientes que permiten trazar líneas de análisis de carácter crítico-comparativo entre los distintos poemarios de la autora. Si bien nos hemos propuesto un abordaje minucioso que pretende recuperar aportes teóricos de variada procedencia, las reflexiones anteriores nos permiten vislumbrar apenas algunos de los vectores que operan en el vasto universo poético comprendido por la escritura de Biagioni, cuyos alcances merecen ser explorados aún con mayor profundidad y detenimiento en el futuro.

$\mathrm{Su}$ trayectoria poética supone un itinerario laberíntico en el que se ponen en juego problemáticas complejas. En un primer momento, en relación con la subjetividad, cuestiones vinculadas con la identidad, la introspección, la experiencia amorosa y el ensimismamiento, que posteriormente derivan en la inestabilidad, el descentramiento y, ulteriormente, el estallido del yo. En cuanto al lenguaje, una impronta comunicativa inicial y cierto conjunto de reglas formales de composición que luego devienen en una explosión polisémica, en una experiencia radical de escritura que involucra la utilización de procedimientos textuales diversos $\mathrm{y}$, fundamentalmente, un trabajo discursivo que juega constantemente con la torsión del signo lingüístico.

Nos encontramos frente a una obra que parte de una impronta estética clásica y un trabajo con la retórica propio de la lírica tradicional, para luego incurrir en una práctica transgresora que supone un giro de doble tenor, el cual opera como desvío y movimiento circular de manera simultánea y complementaria, logrando condensar un gesto de instauración-abolición que impide fijar un único parámetro para clasificar la obra de Biagioni. La afirmación 
inicial de la subjetividad y el lenguaje funciona como condición de posibilidad para la concreción de un segundo movimiento, esta vez de quiebre. Siguiendo el planteo de Deleuze acerca del rizoma, "hay ruptura (...) cada vez que líneas segmentarias explotan en una línea de fuga, pero la línea de fuga forma parte (...). Estas líneas no dejan de remitirse las unas a las otras. Es por esto por lo que jamás se da un dualismo o una dicotomía" (24). Así, las líneas segmentarias presentes en los primeros poemarios, estallan en líneas de fuga que tienden lazos múltiples. Si bien la inflexión que opera en el tercer poemario de Biagioni implica una modificación y trae aparejada la implantación de un régimen de lectura diferente, también funciona como una posibilidad de retomar lo anterior para construir deconstruyendo y, en términos de Deleuze y Guattari, territorializar desterritorializando. La obra de Biagioni transita, en este sentido, un camino de proyección y avance (retro)activos, en el que la renovación y el cambio -al mantener ciertas continuidades como la musicalidad, la religión, el movimiento o la veta cosmológica- se definen por contacto con lo anterior, acentuándose por su carácter contrastivo y especular a la vez, sin que esto implique una desjerarquización del movimiento de escritura inicial, sino mas bien su consolidación bajo un talante diferente, su reinscripción en el plano de un recorrido que dista de ser lineal. Es justamente en esa ambivalencia fundamental donde radica la transgresión y alteridad de una propuesta poética consolidada en el libre despliegue del lenguaje e impulsada por una de las escritoras más osadas y originales del campo literario argentino del siglo XX. 
CATEDRAL TOMADA: Revista literaria latinoamericana / Journal of Latin American Literary Criticism

Amelia Biagioni o el imprevisible trayecto de una experiencia poética alterna

\section{Bibliografía}

Barthes, Roland. Crítica y verdad. Buenos Aires: Siglo XXI, 1976.

Biagioni, Amelia. Poesía completa (Edición a cargo de Valeria Melchiorre) Buenos Aires: Adriana Hidalgo editora, 2009.

Bordelois, Ivonne. "Amelia Biagioni: la fiesta desplegada". La Nación. 24 oct. 2009 Cultura. http://www.lanacion.com.ar/1188614-amelia-biagioni-lafiesta-desplegada.

Bordelois, Ivonne (et. al). Amelia Biagioni. Buenos Aires: Ediciones del Dock, 2012

De Peretti, Cristina. "La práctica textual y sus estrategias" en Jacques Derrida: Texto y deconstrucción. Barcelona: Anthropos, 1989.

Deleuze, Gilles y Guattari, Félix. Rizoma. 1972. Valencia: Pre-textos, 1976

Derrida, Jacques. "Entrevista con Jean- Louis Houdebine y Guy Scarpeta". Posiciones. Valencia: Pre-textos, 1977.

Kristeva, Julia. "Poesía y negatividad" y "El engendramiento de la fórmula". Semiótica2. 1969. Madrid: Espiral/ensayo, 1981. 55-216

Kristeva, Julia. "La palabra, el diálogo y la novela" y "Para una semiología de los paragramas" en Semiótica 1. 1969. Madrid: Fundamentos, 2001. 187-255

Melchiorre, Valeria. "Amelia Biagioni: una identidad en fuga por el lenguaje errante" en: Espéculo. Revista de estudios literarios. Universidad Complutense de Madrid, 2003. http://www.ucm.es/info/especulo/numero23/biagioni.html.

Melchiorre, Valeria. "A manera de presentación” en Amelia Biagioni: Poesía completa, Buenos Aires: Adriana Hidalgo Editora, 2009.

Melchiorre, Valeria. Amelia Biagioni: la "ex-centricidad" como trayecto. Buenos Aires: Corregidor, 2014 
Moure, Clelia. "Voces y materias en Amelia Biagioni: la escritura como devoración/generación" en Piña, Cristina (ed.) Mujeres que escriben sobre mujeres (que escriben) Volumen II. Buenos Aires: Biblos, 2003. 109-140

Moure, Clelia. "Yo persigo el escondite de la ardiente metamorfosis" en Amelia Biagioni. Buenos Aires: Ediciones del Dock, 2012. 81-95

Piña, Cristina. “Amelia Biagioni: la 'salida fuera del libro' como articulación concreta del "libro que vendrá", Actas del $1^{\circ}$ Congreso Regional del Instituto Internacional de Literatura Iberoamericana, 2003. http://www.geocities.ws/aularama/ponencias/opq/pina.htm. Última consulta: 25/10/2015.

Piña, Cristina. "Amelia Biagioni: una poética de la ruptura", en Piña, Cristina y Moure, Clelia. Poéticas de lo incesante. Sujeto, materialidad y escritura en Amelia Biagioni y Néstor Perlongher. Buenos Aires: Botella al Mar, 2005. 13-99

Real Academia Española. Diccionario de la lengua española $\left(22^{\circ}\right.$ ed), 2001. Consultado en http://www.rae.es/rae.html

Zonana, Víctor (2007). "Introducción" en Poéticas de autor en la literatura argentina (desde 1950). Buenos Aires: Corregidor. 15-44 